\title{
DD Young
}

\section{Conditions for a Digital Metaphysic}

\begin{abstract}
Through an interpretation of Plato and Aristotle, I argue that the founding values of traditional metaphysics were made possible by specific conditions of language and metaphor. Using the premises drawn from these Greek philosophers, I evaluate the ways digital media do and do not diverge from those conditions. In order to comprehend the novelty of digital media theoretically, we must first understand which features of 'thought' are conserved between different media systems. My position contrasts particularly with that of N. Katherine Hayles who, in My Mother was a Computer (2005), asserts that the novelty of digital media renders the conceptual resources of 'traditional media' inadequate to theorize it. Most of Hayles's analysis and comparison is devoted to the properties of digital code and the interaction between code and hardware. I argue, by employing a semiotic division of language between syntagmatic and associative axes, that programming languages lack the semantic indeterminacy required to constitute a new worldview, as Hayles proposes. Finally, I argue that Hayles's argument fails to articulate specifically how epiphenomena come to affect thinking. While there are differences between print and digital text, instead of looking to epiphenomenal causation, I propose a line of inquiry that would compare their histories as systems. Far from casting off traditional metaphysics, digital technology may actually better approximate some of their goals, for it enables a more thorough self-erasure of its own material which never comes into a phenomenal purview.
\end{abstract}

KEYWORDS: Media Theory, Digital Humanities, Metaphysics, Visual Culture

a

With regards to the conditions of a metaphysic generated by the operations of digital media, my tact is conservative: I argue that traditional metaphysics were made possible by specific material and conceptual conditions, particularly by metaphor and text, and I propose to evaluate the ways digital media fall in line with these conditions. In order to comprehend the novelty of digital media as theoretical objects, we must first understand which features of 'thought' are conserved between different systems of mediation. My position contrasts in particular with that of N. Katherine Hayles who, in My Mother was a Computer (2005), asserts that the 
new features of digital media render the conceptual resources of 'traditional media' inadequate. Most of Hayles's analysis and comparison is devoted to the properties of digital code and the interaction between code and hardware. Yet, for most users, most of the time (with the exception of programmers and engineers) both the code and the material causes are epiphenomenal. Even if a user acknowledges these systems operate in parallel or have a causal connection to the resultant phenomena, these process themselves remain imperceptible. Nevertheless, Hayles argues that these systems have an immediate effect on the thought of their users. I take issue with this formula, for the argument itself is structured by the conventions of a metaphysic bound to a written medium, text; if written media are 'remediated' into digital media, and this shift changes thought in some way, we must first attend to the form and system of theory itself in order to establish a position from which causal relationships between media and thought can be measured. If a change in thinking brought about by the transition from one medium to another is to be thought theoretically, we require a more precise account of the causal relationship from medium to theoretical system.

There are variations of what Hayles calls traditional metaphysics. To delineate the basic character of metaphysics in this context, we turn to Aristotle's Metaphysics, where the object of this science is first given explicitly. According to him, the purpose of a metaphysic is "knowledge having to do with certain principles and causes" (1998: §982a), that is, those principles and causes which subtend all orders of knowledge. Immediately after, Aristotle divides theoretical from technical knowledge. The senses, for him, are an inadequate means for theoretical knowledge, "for sense perception is common to all men and...not wise at all" (1998: §982a). This theme persists in other metaphysical traditions, including those of Descartes and Husserl. One who loves wisdom, conversely, strives for "universal knowledge. For this man in a way knows all subjects, and more or less also the hardest for men to know, those that are the most general - for these are the furthest removed from the senses" (1998: §982b). While the object of theoretical knowledge is general, it is the actual substance of sensible knowledge and persists in every sensible knowing, even if it is not recognized. Aristotle uses the example of fire to illustrate how knowledge varies among knowers: while everyone, even animals and children, may know that fire is hot, only the wise can speculate as to why it is hot. Both are forms of knowing, but the second is superior, rarer, and more difficult to attain. The object of metaphysics for Aristotle is the substantial cause of the experience of a being's properties, in particular, those attained sensibly. Inversely, acquiring technical knowledge only requires considering properties as they appear (that is, phenomenally). The cause of fire's heat is general and it can be rationally deduced from the experience of heat that this property belongs to its specific substance or being (ousai). Like sensory knowledge, which corresponds to bodily organs, theoretical knowledge has a corresponding organ in the perceiver-the mind, or noos. 
A metaphysic is thus a theoretical science, a noetic (from noos) 'perspective' that associates visible appearances with their invisible causes-metaphorically, it 'sees' what cannot be seen. The metaphoric relationship between vision and knowledge has animated metaphysics from the start: Socrates, for example, declares in the Republic that "the soul is like the eye: when resting upon that on which truth and being shine, the soul perceives and understands and is radiant with intelligence" ( $\$ 508 \mathrm{~d})$. Likewise Aristotle elevates vision as the crown of sensory knowledge, for "sight is the sense that especially produces cognition in us and reveals many distinguishing features of things" (1998: \$980a). Plato and Aristotle's association of vision with knowledge has its precedent in the Greek language: theoria, the etymological root of 'theory,' conjoins thea, a 'view,' with orao, the verb 'to see.' Additionally, there is a close relationship between this particular 'view' and the divine, as thea and theos render the divine in its feminine and masculine forms respectively: for example, theoreion names an emissary sent to see an oracle, a god-seer. A defining feature of metaphysics, the theoretical science, is one of perspective as over-view or that view granted by the divine; theoretical knowledge is, according to Aristotle, "above the herd" (1998: §981b). According to this vertical measure, knowledge begins in common sensibility, with sight and perception, but wisdom, the divine gift, elevates the mind from its mean condition. True knowledge relativizes mere appearances to their specific causes (material, formal, efficient, and teleological). Metaphysics is thus the science "which a god would most choose...for god is thought to be among the causes for all things and to be a kind of principle, and also god would have such knowledge...exclusively" (Aristotle 1998: §983a). The essence of metaphysics is a perspective from a divine eye, or (as we are more likely to call it) a worldview.

The analogy of sight with knowledge — and by extension, light with truth — is found at the heart of theoretical methods, and it illuminates Occidental philosophy from the Pythagoreans to Husserl to such an extent that Jacques Derrida names it "the founding metaphor of Western philosophy as metaphysics..... and in this respect the entire history of our philosophy is a photology, the name given to a history of, or treatise on, light" (1978: 27). The metaphysical notions of causality and knowledge are inseparably intertwined with the photologic metaphor. An exemplary case is Socrates's cave allegory, wherein the division of actual from obscured sight is analogous to the division of true from illusory knowledge. Today, we practice the metaphor wherever we refer to the 'clarity' of an argument, the 'obscurity' of a definition, the 'scope' of a thesis, or put theory itself under 'review.' Theory is a conceptual perspective on the invisible relationships between things (both aesthetic and noematic) and the principle causes by which they appear to their correspondent organs-either the eye of the body, or that of the mind.

Drawing invisible causes into view pertains to theories of media. In every case cited thus far, and the very condition for citation in the context of written media, thought is revealed as text. Only for being inscribed in Plato's text does the trace 
of Socrates's speech persist. Here we also see the first impasse of the problematic relationship between thought and medium; which is original? Do written media mark the appearance of the antecedent thoughts that caused them? Or do written media generate thought according to its particular character? There is a problem of deference which prevents us from presenting the concept (from within a medium, this writing system) of a causal link from 'medium' to 'thought,' or vice versa. We are caught trying to distinguish cause (medium or thought) and effect (thought or medium) retrospectively from a position always, in advance, caused by the other side of the relationship we are trying to theorize, like an eye trying to view itself seeing. Perhaps it is the case that the perspectival metaphor in writing, a visible material, is a determined generation: text itself ranges over the division of knowledge from eye to mind as thought appears on a visible page. The Toronto School of communications theory has focused on the effect of writing on Western consciousness on a grand scale and its body of work on media theory catalogues the effects of writing (and other media) on cultural behaviour and thought, with different emphases. For those associated with this school, Western thought is a product of the defining features of the phonetic alphabet. According to Walter Ong:

[T] he lodging of speech in space which culminated in the development of alphabetic typography was not an isolated phenomenon. It was...part of a widespread reorganization of the sensorium favoring the visual in communication procedures, that is, favoring the visual in association with the use of words. (1967: 50; emphasis added)

Marshall McLuhan similarly notes that "phonetic technology fostered visual continuity and individual point of view" (1994: 113). Such analyses include, by extension, the various metaphysical traditions' reliance upon visual metaphors, in which the method of thinking is caused by its phenomenal structure. Eric Havelock, also associated with the Toronto School, asserts this plainly:

Between Homer and Plato, the message of storage [or medium] began to alter, as the information became alphabetised, and correspondingly the eye supplanted the ear as the chief organ employed for this purpose. The complete results of literacy did not supervene in Greece until the ushering in of the Hellenistic age, when conceptual thought achieved as it were fluency and its vocabulary became more or less standardised. Plato, living in the midst of this revolution, announced it and became its prophet. (1963: vii)

Explicitly, for Havelock, writing's effect on thought resulted in a formal revolution of wisdom and education from the pre-Platonic, poetic/oral practice to a conceptual form directly facilitated by the characteristics of alphabetic writing.

Although I maintain that the deference of cause-to-effect or effect-to-cause remains aporetic, the Toronto School authors confidently adhere to the formula that the form (and the phenomenal form in particular) of the medium causally determines thought. We will adopt this formula for argument's sake, yet we should first note 
the differences between Platonic or Aristotelian metaphysics, and the cause/effect relationship between medium and thought as articulated by Ong, McLuhan, and Havelock. Plato and Aristotle, as we have shown, construct a hierarchy of thought ranging from vulgar to lofty storeys, from doxa to episteme, or from mere opinion to knowledge. For them, the idea or special substances are the first causes of knowledge, even if we only come to knowledge of them after a process of mental elevation. For the Toronto School, conversely, the first causes of the eventual effects, such as 'behaviour' or 'culture, instead belong to the sensible experience of written language. While the causes and effects are inverted, what persists is the fact that theorists can only perceive basic causes after having ascended to a level of theoretical knowledge. For the Toronto School, we ascend this ladder through the habitual initiation into the writing system. For Plato and Aristotle, we ascend it by the right use of reason, in order to view the highest idea or the most general substance that was previously unknown; yet in retrospect we can come to realize what were the true causes all along.

Also corresponding with the Greek metaphysicians, there is for the Toronto School an experience of progressive levels in the ascent to literacy. For example, the child or the animal may see the written page and yet lack the intelligible perception of the associations thereon. We, as practiced readers, habitually 'perceive' the meaning as if 'looking' through the surface onto a second region. This region can be distinguished from its material form as its content or its meaning. The experience of intelligible perception is notably absent when we see a page of writing in an alien language, even as we recognize it as writing. To account for the appearance of division, we must somehow delineate material from medium, a delineation that many media theorists, including the Toronto School, seem to overlook. Although the material and the thought it mediates emerge together inextricably, experiencing one separate from the other hints at a relation which includes something in-addition-to sensory vision. A system of writing may be a medium, but it may also be recognized as as such without being intelligible. If we accept the previously articulated formula that the features of a medium are among the causes of the mode of thought generated by it, we could argue from this premise that Aristotle's Metaphysics, for example, expresses the features of writing itself, albeit unconsciously. The written medium in systematic operation, or what I shall call text, also faces another region other than its material, one which appears alongside the marks on its face, but is not identical with it. A medium is in between, and text, as medium, ferries the experience of two faces: one that is visible, and one that is intelligible or not. As such, we find ourselves again in the metaphysical division, as Plato named the two sides of the division the visible (before vision) and intelligible (beyond the visible). Theoretical knowledge crosses the schism by employing the vision/knowledge metaphor. Writing becomes the medium I have referred to as "text" in a temporal process by which the visible and intelligible meanings appear together, and, in contrast with mere writing, text serves as a theoretical medium. 
In the scheme of metaphysics, the science of causes, the region of text that appears alongside phenomena is the intelligible. It operates in the writing of the Greeks while its causal relationship to sensory experience is inverted by the Toronto School. Ong and McLuhan's articulation of alphabetic writing as a cause for the thought of Western culture recalls the text's invisible face while they theorize about it. Even within a causal relationship that emphasizes the material form, the vertical structure of a knowledge hierarchy is repeated - that is, they defer to the division technical medium and theoretical thought. This is not a reason to discount their analyses, but a broader perspective of the concept of medium remains to be sought. Their theories of alphabetic writing operate having always already appropriated the 'perspective' of theory - a feature evinced by their method of laying out the history of media as a plane. To objectify history such that vast portions of it offer themselves up for analysis is a worldview constructed by the scaffold of the perspectival metaphor. Ong, McLuhan and Hayles each describe the material forms of old and new media, making no distinction between 'medium' and 'matter'; yet their theories are replete with the fossilized metaphors of vision, an invisible referent which exceeds material composition per se.

N. Katherine Hayles's explicit goal in My Mother was a Computer is a "nuanced analysis of the overlaps and discontinuities of code with the legacy systems of speech and writing... [for] they do not emerge unchanged from the encounter with code" (2005:38). Hayles goes on to list those properties of code that constitute new or emergent emphases. These properties include an increased materiality (42), the direct relation of signifier and signified (47), quicker obsolescence (51) and stricter hierarchy (54), among others. The list of formal differences, Hayles opines, makes clear why we cannot afford to ignore code, for if we cannot understand the dynamics that "happen before (or after) any human interpretation of these messages" (47), we will fail to recognize the effects of code, qua medium, on thought.

The inadequacy of this argument, thus presented, is its implication that the argument is somehow extraneous to the textual medium by which it appears. The content of thought is somehow being remediated into digital code, yet the medium is still text. Hayles's thought appears as text, yet the issue of distinguishing cause from effect is not so easily settled-if what she says regarding the boundary between thought and medium is true, then 'thought' in every context is already an effect of the media she purports to compare. That is, the theoretical perspective concerning the causes and effects of media can be extracted from its particular medium in order to 'see' from alternative worldviews. For example, Hayles offers invitations such as, "Let us now consider how this claim...looks from the point of view of code" (2005: 46 ) in order to locate the unperceived effects of code on our thinking. However, this transplantation of the noetic perspective into "the worldview of code" $(46,47)$ is not accomplished through the medium of code, but the medium of text. "We," when comparing traditional and new media, are neither looking from the "point of view of code" nor the "point of view of writing," we are looking from the point of view 
of a theoretical metaphysic, scaffolded by the text's schema and its ancient vision/ knowledge metaphor. Hayles states that, "[C]ode may inherit little or no baggage from classical metaphysics" (51); however, the perspective that permits a theorist to write about code operates precisely by the conditions granted by traditional metaphysics. Hayles's arguments and analysis operates by, supposedly, shedding their written form in order to see-as-if-from code. This operation is an illusion, of course, and to name it as such is not to disparage it, but to acknowledge a particular power of this medium. Using the medium of text to theorize the relationship of code to thought requires that theoretical text and the form of thought correlated with it replaces code, bringing it into a textual system which speaks in its place. Whence then is code's point of view?

The very condition for a worldview is the subtending metaphor that bridges the sensible and intelligible faces of a medium. In the structure of code and its elements, there is neither a function for indeterminacy nor metaphor, and, I argue, it cannot therefore open as worldview. Operationally, a metaphoric relationship functions between multiple, invisible referents along an associative axis. As an element of language, the meaning (or function) of the metaphor is indeterminate, and as such, even the same metaphor can defer to multiple indices at once, rendering a range of possible semantic values. Code, on the other hand, is a syntagmatic sequence of elements and sub-elements, and does not require an associative axis to function. Rather, each element, tag, property or function corresponds to a determinate referent in a single index (called a library) specified in advance; in a programming language, there is no associative axis because there can be no semantic indeterminacy. In Writing and Difference (1978), Derrida articulates how indeterminacy is precisely that which makes theoretical language possible:

$[\mathrm{O}]$ ne must refer to language's peculiar inability to emerge from itself in order to articulate its origin.... In order to respect this strange movement within language, in order not to reduce it in turn, we would have to attempt a return to the metaphor of darkness and light (of self-revelation and self-concealment), the founding metaphor of Western philosophy as metaphysics. The founding metaphor not only because it is a photological one- and in this respect the entire history of our philosophy is a photology, the name given to a history of, or treatise on, light-but because it is a metaphor. Metaphor in general, the passage from one existent to another, or from one signified meaning to another... is the essential weight which anchors discourse in metaphysics, irremediably repressing discourse into its metaphysical state. (27)

There is much to parse here, some of which I have already cited. First, Derrida notes the inability of language (as writing) to articulate its own origin as a result of metaphoric associations playing within that very inscription: this is, again, the aporia of deference to an original cause/effect relationship between medium and thought. This same deference is that which makes semantic indeterminacy possible, 
and indeterminacy is a feature that programming languages do not tolerate in any degree. Theoretical language can pretend to express its own exterior, yet this pretence is made possible by the medium by which it crosses its inherent division, inscribing itself in its two regions at once as thought and medium. Crossing the pleat between intelligible and visible is the function of the metaphoric in language (as a feature of the system, one that extends beyond particular metaphors) and this theoretical movement requires a play of differential signification between its elements, existents or signifieds; this is a condition for theoretical text, and a condition that digital code cannot satisfy.

As I have argued, theoretical text becomes thought by continued passage over that primal fold between the visible and intelligible regions. With Derrida, we recognize the basis of theory is not itself theoretical, and the structural integrity of a metaphysic is supplemented by the system's environment, not the system itself. These supplements are the "traces" of the intelligible region, which have no determinate being themselves except in relation to the system they sustain. Regional play is a condition for metaphysics as such: "Metaphor in general, the passage from one existent to another, or from one signified meaning to another... is the essential weight which anchors discourse in metaphysics" (Derrida 1978: 27). There can be no "worldview of code" precisely because the elements of this system do not tolerate semantic indeterminacy in signification. In fact, Hayles herself confirms the impossibility of indeterminacy, and therefore the play of metaphor, in the language of code:

In the context of digital computers, even less tenable than ambiguity is the proposition that a signifier could be meaningful without reference to a signified....In the worldview of code, it makes no sense to talk about signifiers without signifieds. Every voltage change must have a precise meaning in order to affect the behaviour of the machine; without signifieds, code would have no efficacy. $(2005: 46,47)$

However, Derrida's critique of Ferdinand de Saussure (which is here referenced implicitly) is not that the signifier is without a signified, for then it would be meaningless, or purely absent. The signified's absence is only meaningful while the absent is marked by a trace; a trace is the present element which marks the absence of the reference (cf. Derrida's Of Grammatology, 1997: 18). The trace is on the surface of text, not in the machine, for there it would be invisible. For Derrida, as Hayles notes, the play of difference is the condition for language itself:

Nor does code allow the infinite iterability and citation that Derrida associates with inscriptions.... "A written sign carries with it a force that breaks with context, that is, with the collectivity of presences organizing the moment of its inscription. This breaking force is not an accidental predicate but the very structure of written text." Although Derrida asserts that this iterability is not limited to written language but "is to be found in all lan- 
guage" (Limited Inc, 10), this assertion does not hold true literally for code, where the contexts are precisely determined by the level and nature of the code.

(Hayles 2005: 48; emphasis added)

The resolution of this contradiction is simple - I argue that we should to give up the presumption that programming languages are languages in terms of their axes of signification, or analogous in their equivalent capacity to maintain worldviews. Conversely, Hayles argues instead that code is a 'language' without a differential structure. This is problematic because it is changing an essential condition of the theoretical language Hayles utilizes. Furthermore, code cannot permit even the most obvious (that is, obvious to language users) relations on the associative axis of language- for as anyone who has spent time debugging knows, the smallest punctuation mark out of place can cause an application to hang; the property of 'background color' in HTML code is absolutely dissimilar to 'background colour,' which has no function whatsoever. This is not to say that digital code is not a medium at all, only that what is being mediated is not theoretical knowledge.

In any semantic writing, a relatively high degree of variance in convention and vocabulary remains comprehensible to the habituated reader. Furthermore, reading a translated work, watching different theatre productions based on the same script, or listening to an audiobook provides sufficient common substance for a concept of the "work" indicating that some coherence persists over time despite the variety of material phenomena with which they appear. This recognition of the coherence of a work, while not stable in a transcendent sense, persists in a way that exceeds the material alone. Metaphysicians have long sought the substance that makes such continuity possible. Hayles, instead of engaging this question, simply declares outright that, "[t]here is no Platonic reality of texts. There are only physical objects such as books and computers, foci of attention, and codes that entrain attention and organize material operations" (2005: 97). This assertion of what is jettisons with it the entire structure that made her shifts in theoretical perspective possible in the first place, and with that structure, the possibility of a standard by which to measure one worldview with another.

Theory belongs to the medium of text. The digital is not a replacement of text as a medium of thought, however, it can be a substitute for its surface, the screen of pixels, for example, in place of paper and ink. That is, you will recognize text as medium on a screen as material. We, as a particular observer perceive text on the screen as having both associative and syntagmatic axes. Yet, we cannot at the same time "look" inside the computer at its physical changes in voltages without changing our theoretical position; the perspective shifts from one of visible, phenomenal causation to one that it is epiphenomenal and hidden away, without a trace, in the machine. The material of paper, ink, and screens are all experienced phenomenally, even before they incite perception or cognition. However, there are also material causes of these phenomena that are known as causes but never experienced as such. 
This category includes the ingredients of the ink, the pulp from which paper is produced, the ferromagnetic switches inside a digital device and the code that computes to display an interface. Hayles dedicates much of her book to determining the effects of epiphenomena on thought "before (or after) any human interpretation of these messages" (2005: 47). She proposes that digital "processing is necessarily prior to whatever cognitive processing the user performs to read and interpret the text" (2005: 101; emphasis added). While a metaphysic may determine causal sequences of knowledge, Hayles denies metaphysics on the one hand, but then argues that matter is the first cause of "cognitive processing", even if that matter is never experienced, only known. We might say it belongs to an invisible face. This assertion is metaphysical, having to do with certain, imperceptible causes. In this respect, Hayles locates the special substance of thought (which, incidentally, is analogized with computing by calling it 'processing') in an invisible, untraceable, absent region just as Plato and Aristotle locate it in the idea or substance. These conditions make it possible to think the causes of thought belong to metaphysics, and Hayles's argument is metaphysically contiguous with its traditional, textual antecedents.

Text as medium is contiguous over the change in material causation from print to screen. Hayles argues for a shift in thought based only on a purported change in epiphenomena, even if this change is imperceptible within the medium, yet takes this region to be the ultimate cause of thought. As I have argued throughout, these specific changes fall short of the promised revolution of thought. However, there are other differences between print and digital text in terms of their histories as systems and how these histories involve thought; within these differences the uniqueness of digital metaphysics may be sought. For example, reduced spatial requirements by digital memory and the access and speed of networked devices may actually approximate the goals of traditional metaphysics better than text, for it enables a more thorough self-erasure of its own material, which never comes into view (as computation occurs imperceptibly within a black box). We must give due attention to both the hidden face and the surface of a medium, for without their appearing together there can be no mediation. The phenomenal matter of the text medium - whether stone, skin, paper, or pixel — are always a condition for deference to the hidden face, and they yield traces of that hiddenness. On the other hand, we must stop short of an outright declaration that "[t]here are only physical objects" (Hayles 2005: 97), for this is already a metaphysical declaration that immediately renders itself inadequate once we distinguish medium from matter. Theorizing the digital as a medium requires an extension of old concepts, and an entire invisible structure therewith, into a novel phenomenal experience.

\section{References}

Aristotle. 1998. The Metaphysics, translated by H. Lawson-Tancred. London: Penguin Books. 
Derrida, Jacques. 1978. "Force and Signification.” Writing and Difference, translated by Alan Bass. Chicago: The University of Chicago Press. 3-30.

---. 1997. Of Grammatology, translated by Gayatri Chakravorty Spivak. Baltimore: John Hopkins University Press.

Havelock, Eric A. 1963. Preface to Plato. London: Harvard University Press.

Hayles, Katherine N. 2005. My Mother was a Computer: Digital Subjects and Literary Texts. Chicago, University of Chicago Press.

McLuhan, Marshall. 1994. Understanding Media: The Extensions of Man. Cambridge: MIT Press.

Ong, Walter J. 1967. The Presence of the Word. New Haven: Yale University Press.

Plato. 2000. Republic, translated by Benjamin Jowett. Mineola: Dover Publications. 